\title{
Effect of Dopants on Zirconia Stabilization-An X-ray Absorption Study: III, Charge-Compensating Dopants
}

\author{
Ping $\mathrm{Li}^{\star}$ and I-Wei Chen ${ }^{\star}$ \\ Department of Materials Science and Engineering, University of Michigan, Ann Arbor, Michigan 48109-2136
}

James E. Penner-Hahn

Department of Chemistry, University of Michigan, Ann Arbor, Michigan 48109-1055

\begin{abstract}
$\mathrm{X}$-ray absorption spectra at the $\mathrm{Zr}$-, $\mathrm{Y}$-, and $\mathrm{Nb}-K$ edges of $\mathrm{ZrO}_{2}-\mathrm{YNbO}_{4}$ solid solutions have been measured at $10 \mathrm{~K}$ to determine the local atomic structures. Both $\mathrm{Y}$ and $\mathrm{Nb}$ cations substitute for $\mathrm{Zr}$ in the cation network but maintain rather different local oxygen coordination from $\mathrm{Zr}$. In tetragonal zirconia solid solutions, $Y$ adopts a $\mathrm{YO}_{8}$ structure with a bond length of $2.32 \mathrm{~A}$. This is the same as the structure found in $\mathrm{ZrO}_{2}-\mathrm{Y}_{2} \mathrm{O}_{3}$ solid solutions, confirming our previous conclusion that $Y$ is not associated with oxygen vacancies. $\mathrm{Nb}$ has an $\mathrm{NbO}_{4}$ structure with a bond length of $1.90 \AA$. This is shorter than the $\mathrm{Zr}-\mathrm{O}_{\mathrm{I}}$ distance of $2.10 \AA$. The strong $\mathrm{Nb}-\mathrm{O}$ coordination increases the bonding disparity between $\mathrm{Zr}-\mathrm{O}$ layers, thus increasing tetragonality. This is similar to the trend previously established for $\mathrm{ZrO}_{2}-$ $\mathrm{GeO}_{2}$ solid solutions. Severe distortion of neighboring cations around the undersized $\mathrm{Nb}$, similar to that previously found for undersized $\mathrm{Fe}^{3+}$ and $\mathrm{Ga}^{3+}$, is also observed. At higher temperatures, local $\mathrm{Y}-\mathrm{Nb}$ cation ordering occurs at a concentration below the solubility limit, similar to the $\mathrm{Zr}-$ Ge ordering reported previously. This cation ordering mechanism allows the charge-compensating $\mathrm{Y}-\mathrm{Nb}$ pair to stabilize the tetragonal structure but increase tetragonality.
\end{abstract}

\section{Introduction}

$\mathbf{F}$ LUORITE-STRUCTURED oxides typically have considerable solubility for divalent, trivalent, and tetravalent cations, but their solubility for pentavalent cations is usually low. In $\mathrm{CeO}_{2}$, the solubility on $\mathrm{Nb}_{2} \mathrm{O}_{5}$ is below $0.8 \mathrm{~mol} \%$.' For $\mathrm{ZrO}_{2}$, very low solubility for $\mathrm{Nb}^{5+}$ and $\mathrm{Ta}^{5+}$ is also reported. ${ }^{2.3} \mathrm{~A}$ much larger solubility, however, can be obtained if $\mathrm{Nb}^{5+}$ or $\mathrm{Ta}^{5+}$ is codoped with a divalent or trivalent cation, as demonstrated in the $\mathrm{ZrO}_{2}-$ $\mathrm{MgO}-\mathrm{Ta}_{2} \mathrm{O}_{5}{ }^{4}$ and $\mathrm{ZrO}_{2}-\mathrm{Y}_{2} \mathrm{O}_{3}-\mathrm{Ta}_{2} \mathrm{O}_{5}$ systems. ${ }^{5,6}$ Ionic conductivity measurements confirmed that, in the latter system, one oxygen vacancy was removed for every two $\mathrm{Ta}^{5+}$ added. Thus, the low solubility for $\mathrm{Nb}^{5+}$ and $\mathrm{Ta}^{5+}$ is obviously due to the difficulty in maintaining charge compensation by mechanisms other than oxygen vacancies in fluorite-structured oxides.

Addition of pentavalent cations to partially or fully stabilized zirconia, e.g., the $\mathrm{ZrO}_{2}-\mathrm{Y}_{2} \mathrm{O}_{3}$ solid solutions, reduces the stability of the higher-temperature polymorphs (cubic and tetragonal) against distortion. ${ }^{7.8}$ Since oxygen vacancies are effective in stabilizing both the cubic and tetragonal structures, ${ }^{9}$ the destabilizing effect of $\mathrm{Nb} / \mathrm{Ta}$ doping can be attributed to the decreased

W. Whitc-contributing editor

Manuscript No. 194508. Received June 3, 1993; approved December 13, 1993. Supported by the U.S. National Science Foundation under Grant No. DMR-9119598. SSRL is operated by the Department of Energy, Office of Basic Energy Sciences. Division of Chemical Sciences, with additional support from the NIH, Biomedical Resource Technology Program, Division of Research Resources and the Department of Energy, Office of Health and Environmental Research.

Member, American Ceramic Society. concentration of oxygen vacancies. The above reasoning, however, cannot be applied to the $\mathrm{ZrO}_{2}-\mathrm{YNbO}_{4} / \mathrm{YTaO}_{4}$ system since oxygen vacancies are neither created nor annihilated. Nevertheless, the tetragonal phase of $\mathrm{ZrO}_{2}$ is stabilized by the addition of $\mathrm{YNbO}_{4} / \mathrm{YTaO}_{4}{ }^{6.7}$ Interestingly, the tetragonality of the $\mathrm{YNbO}_{4} / \mathrm{YTaO}_{4}$-stabilized zirconia actually increases with additive concentration, ${ }^{6.110}$ which is contrary to the observation for all of the divalent and trivalent cation-stabilized zirconia but reminiscent of the $\mathrm{ZrO}_{2}-\mathrm{GeO}_{2}$ solid solutions that we described in the preceding paper." A clear explanation of these disparate phase-stabilizing, structure-distorting effects is not available in the current literature.

The purpose of this study is to use X-ray absorption spectroscopy to investigate the local atomic environments of $\mathrm{Zr}, \mathrm{Y}$, and $\mathrm{Nb}$ in zirconia solid solutions in order to obtain a better understanding of the above issues. $\mathrm{Nb}$ was chosen over Ta because its atomic number is similar to that of $\mathrm{Zr}$ and $\mathrm{Y}$, which is important in maintaining nearly the same X-ray scattering environment regardless of alloy composition. Since $\mathrm{Nb}$ and $\mathrm{Ta}$ have essentially identical size and chemistry, the findings of this study should also be applicable to Ta-containing zirconia. The knowledge gained from this work will be combined with data from our previous studies of other solute cations ${ }^{9,11}$ to provide a coherent picture of the role of stabilizing/destabilizing dopants in zirconia polymorphs. Additional background on the stability of zirconia and a complete list of references to previous EXAFS work on zirconia have been provided elsewhere. ${ }^{9.11 .12}$

\section{Experimental Procedure}

\section{(I) Materials}

Ultrafine powders of zirconia with 10 and $20 \mathrm{~mol} \% \mathrm{YO}_{15}$ $\mathrm{NbO}_{2.5}\left(\mathrm{YNbO}_{4}\right)$ were synthesized by a coprecipitation method using zirconium oxychloride, yttrium nitrate, and niobium ethoxide as starting materials, followed by drying at $250^{\circ} \mathrm{C}$ and calcination at various temperatures. The samples calcined at $850^{\circ} \mathrm{C}$ are designated as $10 \mathrm{YNb} 08$ and $20 \mathrm{YNb} 08$, with the first two digits indicating the mole percent of $\mathrm{Y}-\mathrm{Nb}$. A $10 \mathrm{~mol} \%$ $\mathrm{YNbO}_{4}$ sample calcined at $1400^{\circ} \mathrm{C}$ is designated as $10 \mathrm{YNb} 14$.

Phase identification and lattice parameter determination were made by $\mathrm{X}$-ray diffraction (XRD). The results are summarized in Table I. With 10 and $20 \mathrm{~mol} \% \mathrm{YNbO}_{4}$ addition and calcination at $850^{\circ} \mathrm{C}$, a typical tetragonal zirconia XRD pattern could be identified in spite of peak broadening. With $10 \mathrm{~mol} \% \mathrm{YNbO}_{4}$ and calcination at $1400^{\circ} \mathrm{C}$, a single monoclinic zirconia pattern was observed. This phase is believed to be the product of tetragonal zirconia that transformed during cooling. When the concentration of $\mathrm{YNbO}_{4}$ was increased to $20 \mathrm{~mol} \%$ at $1400^{\circ} \mathrm{C}$ calcination temperature, both tetragonal and monoclinic zirconia were observed, along with a small amount of a monoclinic $\mathrm{YNbO}_{4}$ phase. We believe that in this case the solubility limit of $\mathrm{YNbO}_{4}$ in tetragonal zirconia was slightly exceeded, and during 
Table I. Phase Identification of $\mathrm{ZrO}_{2}-\mathrm{YNbO}_{4}$ Samples

\begin{tabular}{cllc}
\hline \multicolumn{1}{c}{ Sample } & \multicolumn{1}{c}{ Phase } & \multicolumn{1}{c}{ Lattice constants $(\AA)$} & $c / a$ \\
\hline $10 \mathrm{YNb08}$ & $t$ & $a=5.105$ & 1.024 \\
& & $c=5.227$ & \\
$20 \mathrm{YNb08}$ & $t$ & $a=5.114$ & 1.026 \\
& & $c=5.249$ & \\
$10 \mathrm{YNb14}$ & $m$ & $a=5.167, b=5.220$ & \\
& & $c=5.337, \beta=99.06^{\circ}$ & \\
$20 \mathrm{YNb} 14$ & $m+t+m-\mathrm{YNbO}_{4}$ & \\
\hline
\end{tabular}

cooling tetragonal zirconia partially transformed to the monoclinic phase. $\mathrm{YNbO}_{4}$, which has a tetragonal fergusonite form with a scheelite-like structure at high temperature, apparently also transforms during cooling to a monoclinic form. The observation that the solubility of $\mathrm{YNbO}_{4}$ in tetragonal zirconia at $1400^{\circ} \mathrm{C}$ is slightly below $20 \mathrm{~mol} \%$ is in rough agreement with the literature. (At $1500^{\circ} \mathrm{C}$, the solubility of $\mathrm{YTaO}_{4}$ in tetragonal zirconia is reported to be about 22 mol\%. ${ }^{6}$ ) The $20 \mathrm{~mol} \%$ $\mathrm{YNbO}_{4}$ solution that is maintained at $850^{\circ} \mathrm{C}$ is presumably a supersaturation because of the low diffusivity of cations at this temperature.

The unit cell of tetragonal zirconia ( $a$ and $c$ ) expands with the amount of $\mathrm{YNbO}_{4}$, with the expansion in $c$ being larger. Thus, the $c / a$ ratio increases with increasing $\mathrm{YNbO}_{4}$ concentration (see Table 1 ). This result is in agreement with previous studies. $^{6.7 .10}$ The unit cell $(a, b$, and $c$ ) of monoclinic zirconia ( $10 \mathrm{YNb} 14$ ) is also larger than that of pure $m-\mathrm{ZrO}_{2}$, although the angular distortion $(\beta)$ is similar. The above results confirm that solid solutions have been formed in $10 \mathrm{YNb} 08,20 \mathrm{YNb} 08$, and $10 \mathrm{YNb} 14$. These single-phase tetragonal and monoclinic zirconia powders were used in subsequent studies. In addition, pure $\mathrm{ZrO}_{2}, \mathrm{Y}_{2} \mathrm{O}_{3}$, and $\mathrm{Nb}_{2} \mathrm{O}_{5}$ were investigated as model compounds.

\section{(2) X-ray Absorption Measurements}

$\mathrm{X}$-ray absorption measurements at the $\mathrm{Zr}-, \mathrm{Y}$-, and $\mathrm{Nb}-K$ edges were performed using identical procedures as reported previously. ${ }^{11.12}$ Spectra at $10 \mathrm{~K}$ were measured in transmission with the exception of $\mathrm{Nb}-K$ edge spectra for $10 \mathrm{~mol} \% \mathrm{YNbO}_{4}^{-}$ $\mathrm{ZrO}_{2}(10 \mathrm{YNb} 08$ and $10 \mathrm{YNb}$ 14) which were measured in fluorescence mode using a multi-element Ge solid-state detector array. There is no phase transformation between ambient temperature and $10 \mathrm{~K}$ in these powdered specimens. The absorption spectrum of the corresponding pure oxide was recorded as an energy calibration standard at the same time as the sample spectrum. The calibration was defined by assigning the maximum inflection point of the $\mathrm{Zr}-K$ edge in $\mathrm{ZrO}_{2}$ as $17998 \mathrm{eV}$, the $\mathrm{Y}-K$ edge in $\mathrm{Y}_{2} \mathrm{O}_{3}$ as $17038 \mathrm{eV}$, and the $\mathrm{Nb}-K$ edge in $\mathrm{Nb}_{2} \mathrm{O}_{5}$ as $18986 \mathrm{eV}$. Data analysis followed the same procedure as described in the preceding papers. ${ }^{9,11-1.3}$ A quantitative analysis of the cation-oxygen shells was performed using theoretical amplitude and phase functions calculated using $\mathrm{FEFF}^{14}$ with a distance parameter of $2.22 \AA$ for a $\mathrm{Zr}-\mathrm{O}$ pair, $2.28 \AA$ for a $\mathrm{Y}-\mathrm{O}$ pair, and $2.02 \AA$ for a $\mathrm{Nb}-\mathrm{O}$ pair to fit the corresponding cation$O$ shell. Energy values at $k=0, E_{0}$, were initially assigned as $18015 \mathrm{eV}$ for the $\mathrm{Zr}-K$ edge, $17055 \mathrm{eV}$ for the $\mathrm{Y}-K$ edge, and $19005 \mathrm{eV}$ for the $\mathrm{Nb}-K$ edge and then recalibrated so that the cation- $O$ distance from the crystallographic data for pure oxides $\left(2.16 \AA\right.$ for the $\mathrm{Zr}-\mathrm{O},{ }^{15} 2.28 \AA$ for the $\mathrm{Y}-\mathrm{O},{ }^{16}$ and $2.02 \AA$ for the $\mathrm{Nb}-\mathrm{O}^{17}$ ) could be reproduced. The optimum $E_{0}$ value was $18034 \mathrm{eV}$ for $\mathrm{Zr}$ EXAFS, $17076 \mathrm{eV}$ for $\mathrm{Y}$ EXAFS, and $19023 \mathrm{eV}$ for Nb EXAFS. These values for $E_{0}$ were then fixed for all subsequent analyses. Fourier-filter window values for the $\mathrm{Zr}-\mathrm{O}, \mathrm{Y}-\mathrm{O}$, and $\mathrm{Nb}-\mathrm{O}$ shell are given in Table II. Theoretical amplitude and phase functions were calculated for $\mathrm{Zr}-\mathrm{Zr}, \mathrm{Y}-\mathrm{Zr}$, and $\mathrm{Nb}-\mathrm{Zr}$ pairs using FEFF with a distance parameter of $3.62 \AA$. These were used to fit the corresponding $\mathrm{Zr}-, \mathrm{Y}_{-}$, and $\mathrm{Nb}-$ cation shells. Since these three cations have almost identical scattering functions, the error induced by using a $\mathrm{Zr}$ shell to describe an alloy shell $(\mathrm{Zr} / \mathrm{Y} / \mathrm{Nb})$ is negligible.
Table II. EXAFS Results of Cation-O Bonding in the $\mathrm{ZrO}_{2}-\mathrm{YNbO}_{4}$ System

\begin{tabular}{ccccc}
\hline $\mathrm{YNbO}_{4}-\mathrm{ZrO}_{2}$ & $\mathrm{Cation}-\mathrm{O}$ & $R(\AA)$ & $\mathrm{CN}^{*}$ & $\sigma^{2}\left(\AA^{2}\right)$ \\
\hline $10 \mathrm{YNb08}$ (tetragonal) & $\mathrm{Zr}-\mathrm{O}$ & 2.10 & 4.0 & 0.0041 \\
& & 2.36 & 4.0 & 0.0076 \\
& $\mathrm{Y}-\mathrm{O}$ & 2.32 & 8.0 & 0.0112 \\
& $\mathrm{Nb}-\mathrm{O}$ & 1.90 & 4.0 & 0.0036 \\
& $\mathrm{Zr}-\mathrm{O}$ & 2.10 & 4.0 & 0.0049 \\
& & 2.33 & 4.0 & 0.0132 \\
& $\mathrm{Y}-\mathrm{O}$ & 2.32 & 8.0 & 0.0090 \\
& $\mathrm{Nb}-\mathrm{O}$ & 1.90 & 4.0 & 0.0048 \\
& $\mathrm{Zr}-\mathrm{O}$ & 2.16 & 7.0 & 0.0110 \\
& $\mathrm{Y}-\mathrm{O}$ & 2.27 & 7.0 & 0.0072 \\
& $\mathrm{Nb}-\mathrm{O}$ & 1.95 & 4.0 & 0.0056 \\
& & 2.12 & 2.0 & 0.0029 \\
\hline
\end{tabular}

*Fixed during fitting.

\section{Results}

\section{(1) EXAFS Spectra of Cations}

EXAFS spectra at the $\mathrm{Zr}-, \mathrm{Y}-$, and $\mathrm{Nb}-K$ edge for $10 \mathrm{YNb} 08$, $20 \mathrm{YNb} 08$, and $10 \mathrm{YNb} 14$ are shown in Figs. 1-3, respectively. For comparison, the EXAFS spectra for the reference oxides, $\mathrm{ZrO}_{2}, \mathrm{Y}_{2} \mathrm{O}_{3}$, and $\mathrm{Nb}_{2} \mathrm{O}_{5}$, are also shown. Although the signal/ noise ratio is excellent in all cases, only data up to $k=14-15$ $\AA^{-1}$ are used for data analysis because of the presence of the $\mathrm{Zr}-K$ edge at $950 \mathrm{eV}$ beyond the $\mathrm{Y}-K$ edge and the presence of the $\mathrm{Nb}-K$ edge at $988 \mathrm{eV}$ beyond the $\mathrm{Zr}-K$ edge.

$\mathrm{Zr}^{4+}$ in each zirconia polymorph has a characteristic structure which is dopant-insensitive. ${ }^{9.11 .12}$ In Fig. 1 we see that the spectra at the $\mathrm{Zr}-K$ edge are indistinguishable for pure $\mathrm{ZrO}_{2}$ and $10 \mathrm{YNb} 14$, which are both monoclinic. Likewise, the spectra for $10 \mathrm{YNb} 08$ and $20 \mathrm{YNb} 08$, which are both tetragonal, are mutually similar. The decrease in EXAFS amplitude for $20 \mathrm{YNb} 08$ relative to $10 \mathrm{YNb} 08$ is attributed to structural disorder due to random alloying. ${ }^{9.11}$

Turning to the $\mathrm{Y}$ edge, we can differentiate three types of EXAFS spectra in Fig. 2 which correspond to three different phases, C-type $\mathrm{Y}_{2} \mathrm{O}_{3}$, tetragonal $10 \mathrm{YNb} 08$ and $20 \mathrm{YNb} 08$, and monoclinic 10Y Nb14. Likewise, the Nb EXAFS as shown in Fig. 3 can be grouped by their phases, $\mathrm{Nb}_{2} \mathrm{O}_{5}$, tetragonal $10 \mathrm{YNb} 08$ and $20 \mathrm{YNb} 08$, and monoclinic $10 \mathrm{YNb} 14$. Thus, the local environments around dopants are phase-dependent. ${ }^{9.11 .13}$ The $\mathrm{Y}$ and $\mathrm{Nb}$ EXAFS amplitudes for $20 \mathrm{YNb} 08$ are also damped relative to those for $10 \mathrm{YNb} 08$ due to structural disorder.

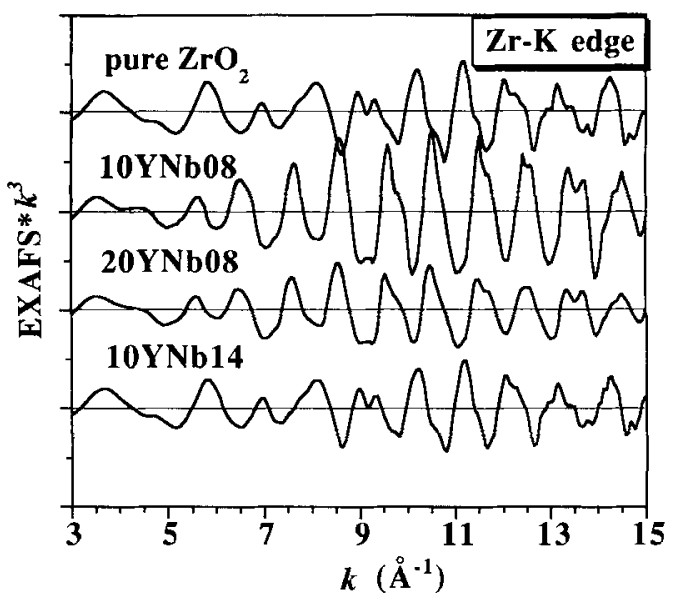

Fig. 1. EXAFS spectra at $\mathrm{Zr}-\mathrm{K}$ edge for $m-\mathrm{ZrO}_{2}$ and $\mathrm{ZrO}_{2}-\mathrm{YNbO}_{4}$ solid solutions. 


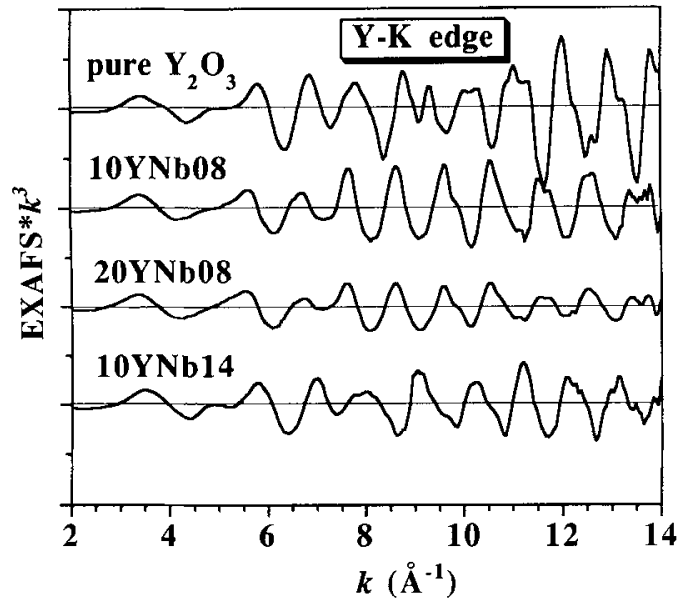

Fig. 2. EXAFS spectra at $\mathrm{Y}-\mathrm{K}$ edge for $\mathrm{Y}_{2} \mathrm{O}_{3}$ and $\mathrm{ZrO}_{2}-\mathrm{YNbO}_{4}$ solid solutions.

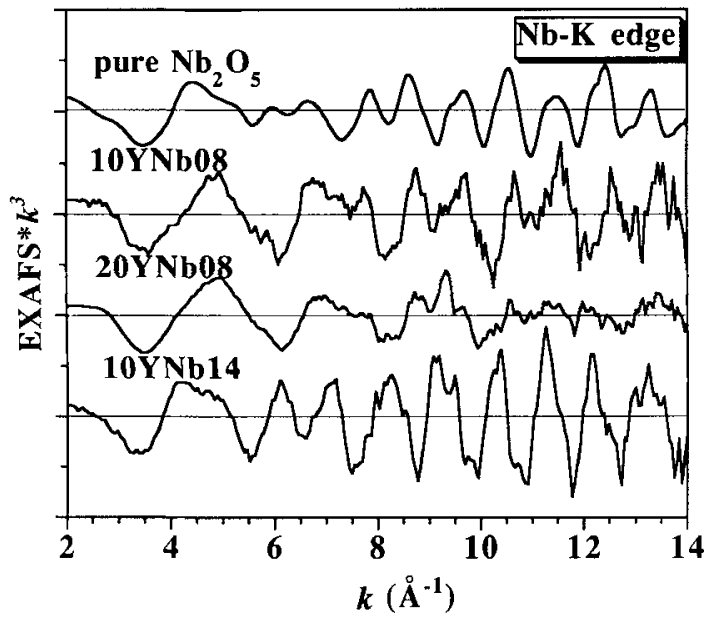

Fig. 3. EXAFS spectra at $\mathrm{Nb}-K$ edge for $\mathrm{Nb}_{2} \mathrm{O}_{5}$ and $\mathrm{ZrO}_{2}-\mathrm{YNbO}_{4}$ solid solutions.

\section{(2) Pseudoradial Distribution Functions around Cations}

(A) Tetragonal Zirconia: Fourier transforms (FTs) of the $\mathrm{Zr}, \mathrm{Y}$, and $\mathrm{Nb}$ EXAFS for tetragonal $10 \mathrm{YNb} 08$ and $20 \mathrm{YNb} 08$ are shown in Figs. 4 and 5. Since $\mathrm{Y}^{3+}, \mathrm{Zr}^{4+}$, and $\mathrm{Nb}^{5+}$ are isoelectronic and have almost identical scattering and phase functions, the Fourier transforms, as pseudoradial distribution functions of the absorber atoms, ${ }^{18}$ can be directly used to compare the structures surrounding each ion. Specifically, the first peak in the FTs corresponds to the nearest neighbors (NN) around the probe cation $(\mathrm{Zr}-\mathrm{O}, \mathrm{Y}-\mathrm{O}$, or $\mathrm{Nb}-\mathrm{O})$, and the second peak corresponds to the next-nearest neighbors (NNN), i.e., $\mathrm{Zr}$ cation, $\mathrm{Y}$-cation, or $\mathrm{Nb}$-cation. The higher-order peaks correspond to outer cation-cation shells.

Comparing these FTs, we find a noticeable two-subshell feature in the $\mathrm{Zr}-\mathrm{O}$ peak in both $10 \mathrm{YNb} 08$ and $20 \mathrm{YNb} 08$, with the outer subshell much weaker in the latter. In contrast, there is only a single resolved cation-O peak for the $\mathrm{Nb}$ and $\mathrm{Y}$ EXAFS. Relative to the $\mathrm{Zr}-\mathrm{O}$ inner shell, the $\mathrm{Nb}-\mathrm{O}$ shell has a shorter distance and the $\mathrm{Y}-\mathrm{O}$ shell has a longer distance. Since $\mathrm{Zr}, \mathrm{Y}$, and $\mathrm{Nb}$ have very similar cation-cation (NNN) distances, both $\mathrm{Y}$ and $\mathrm{Nb}$ substitute for $\mathrm{Zr}$ in the $\mathrm{Zr}$-cation network in tetragonal zirconia solid solutions.

The much lower amplitude of the $\mathrm{Nb}-\mathrm{NNN}$ peak than those of the $\mathrm{Y}$ and $\mathrm{Zr}-\mathrm{NNN}$ peaks in both compositions indicates a significant distortion in the Nb-centered cation network. Similarly, but to a lesser extent, the $\mathrm{Y}$-cation shell is more distorted (lower FT amplitude) than the $\mathrm{Zr}$-cation shell. This was also

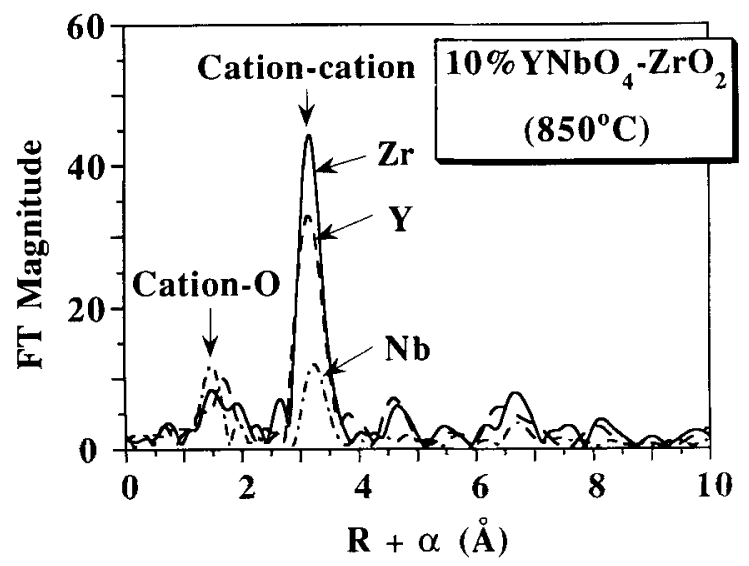

Fig. 4. Fourier transforms of $\mathrm{Zr}, \mathrm{Y}$, and $\mathrm{Nb}$ EXAFS for $t-\mathrm{ZrO}_{2}$ stabilized by $10 \mathrm{~mol}^{2} \mathrm{YNbO}_{4}$ (calcined at $850^{\circ} \mathrm{C}$ ).

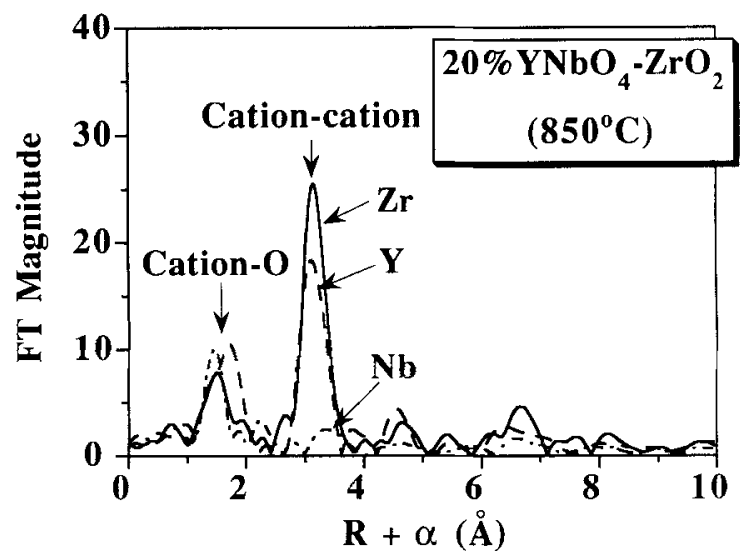

Fig. 5. Fourier transforms of $\mathrm{Zr}, \mathrm{Y}$, and $\mathrm{Nb}$ EXAFS for $t-\mathrm{ZrO}$, stabilized by $20 \mathrm{~mol}_{\%} \mathrm{YNbO}_{4}$ (calcined at $850^{\circ} \mathrm{C}$ ).

found in the tetragonal $\mathrm{ZrO}_{2}-\mathrm{Y}_{2} \mathrm{O}_{3}$ at $10 \mathrm{~K} .^{13}$ The amplitudes of all of the cation networks are significantly smaller for $20 \mathrm{YNb} 08$, a "normal" behavior" because of the increased distortion of the cation network at the higher $\mathrm{YNbO}_{4}$ concentration.

Quantitative fitting results for the cation-O shells are given in Table II. Two sets of bond lengths, 2.10 and $2.33-2.36 \AA$, are found for the $\mathrm{Zr}-\mathrm{O}$ shell in both $10 \mathrm{YNb} 08$ and $20 \mathrm{YNb} 08$. These values are characteristic of tetragonal zirconia. ${ }^{9-11}$ The Debye-Waller factors $\left(\sigma^{2}\right)$ suggest that the distortion of the $\mathrm{Zr}$ $O$ shell increases with increasing dopant concentration. The larger $\sigma^{2}$ for the outer $\mathrm{Zr}-\mathrm{O}$ subshell reflects, in particular, a weaker bond strength. ${ }^{9.11,12,19}$ In $20 \mathrm{YNb} 08, \sigma^{2}$ is so large that the size of the shoulder on the high- $R$ side of the $\mathrm{Zr}-\mathrm{O}$ peak is very weak (Fig. 5).

A bond length of $2.32 \AA$ with 8 -fold coordination is found for the $\mathrm{Y}-\mathrm{O}$ shell in both of the tetragonal solid solutions. These results are also characteristic of $Y$ in tetragonal zirconia. ${ }^{4.13}$ The relatively high bond dispersion indicates a very distorted environment around the Y. A much shorter bond length $(1.90 \AA)$ and lower (4-fold) coordination are found for the $\mathrm{Nb}-\mathrm{O}$ shell reflecting a much smaller ionic size of $\mathrm{Nb}$. (For the coordination number, we first fit the EXAFS data without fixing the coordination. We then choose from among those results that give a satisfactory fit, a chemically reasonable coordination number. This number is fixed in subsequent fitting to obtain the other quantities listed in Table II. The result of 4-fold coordination for $\mathrm{Nb}-\mathrm{O}$ implies that only four oxygens are close to $\mathrm{Nb}$. Other oxygens may be too loosely bound to be visible in EXAFS. (This coordination number is also supported by the following discussion.) Note that the $\mathrm{Y}-\mathrm{O}$ bond length $(2.32 \AA)$ in the 
doped zirconia is larger than that $(2.28 \AA)$ in $\mathrm{Y}_{2} \mathrm{O}_{3}$, while the $\mathrm{Nb}-\mathrm{O}$ bond distance $(1.90 \AA)$ is smaller than that $(2.02 \AA)$ in $\mathrm{Nb}_{2} \mathrm{O}_{5}$. These results are consistent with the change of coordination number ( 6 to 8 for $\mathrm{Y}$ and 6 to 4 for $\mathrm{Nb}$; from pure oxide to zirconia solid solution). These $\mathrm{M}-\mathrm{O}$ distances are also in agreement with those found in tetragonal fergusonite $\left(\mathrm{YNbO}_{4}\right)$, which has a coordination number 8 for $\mathrm{Y}$ and 4 for $\mathrm{Nb} .{ }^{20}$ Interestingly, the distortion of the $\mathrm{Y}-\mathrm{O}$ shell decreases with increasing concentration of dopant $\left(\mathrm{YNbO}_{4}\right)$. In contrast, the distortion of the $\mathrm{Nb}-\mathrm{O}$ shell behaves "normally"; i.e., it increases with increasing dopant concentration. Finally, a quantitative analysis of the second peak in Figs. 4 and 5 shows that the cation-cation distance is essentially the same for all three cations. This distance $(3.62 \AA)$ is characteristic of the $\mathrm{Zr}-\mathrm{Zr}$ distance in tetragonal zirconia, ${ }^{12}$ again confirming that these three cations form a solid solution.

(B) Monoclinic Zirconia: Fourier transforms of the Zr-, $\mathrm{Y}$-, and Nb-K edge EXAFS for $10 \mathrm{YNb} 14$ are shown in Fig. 6. The cation-cation shells (the second peaks in Fig. 6) are now split into three subshells, with their distances approximately the same for all three cations. The peaks correspond well with the peaks in pure monoclinic $\mathrm{ZrO}_{2}$ but not with those in $\mathrm{Nb}_{2} \mathrm{O}_{5}$ and $\mathrm{Y}_{2} \mathrm{O}_{3}$ (Fig. 7). This, together with the XRD results, suggests that both $\mathrm{Y}$ and $\mathrm{Nb}$ have dissolved into the $\mathrm{Zr}$ network and formed a monoclinic zirconia solid solution. Since the monoclinic phase results from a diffusionless transformation of the tetragonal phase during cooling, it also implies that the $\mathrm{Zr}, \mathrm{Y}$, and $\mathrm{Nb}$ form a solid solution in tetragonal structure at $1400^{\circ} \mathrm{C}$, in agreement with our observation for $10 \mathrm{YNb} 08$. (The lower stability of $10 \mathrm{YNb} 14$ compared to $10 \mathrm{YNb} 08$ is most likely due to a larger particle size after high-temperature calcination, favoring monoclinic nucleation. ${ }^{21}$ ) Interestingly, a larger amplitude is found for the $\mathrm{Y}$-cation shell relative to those for $\mathrm{Zr}$ and $\mathrm{Nb}$. This indicates a less distorted $Y$-centered cation network in the monoclinic solid solution. Even more interesting is the fact that the amplitude of the $\mathrm{Nb}$-cation shell is actually very strong in this monoclinic sample whereas it is very weak in both of the tetragonal samples (Figs. 4 and 5). These observations are "abnormal" for a random solid solution" and suggest that $\mathrm{Y}-\mathrm{Nb}$ ordering has occurred at high temperature in the tetragonal phase, and, through phase transformation, this ordered structure is inherited in the monoclinic phase.

Quantitative analysis gives the results shown in Table II. The $\mathrm{Zr}-\mathrm{O}$ shell data are consistent with our previous studies of characteristic structure in the monoclinic zirconia. ${ }^{9.12}$ The $\mathrm{Y}-\mathrm{O}$ shell is also 7 -fold coordinated, with a bond length of $2.27 \AA$. In contrast, two peaks are found for the $\mathrm{Nb}-\mathrm{O}$ shell, with bond distances at 1.95 and $2.12 \AA$ and a total coordination number of 6 . Note that while the mean bond lengths of both $\mathrm{Zr}-\mathrm{O}$ and $\mathrm{Y}-\mathrm{O}$ are shorter in monoclinic zirconia solid solution than in tetragonal zirconia, the opposite is true for the $\mathrm{Nb}-\mathrm{O}$ bonds. This is

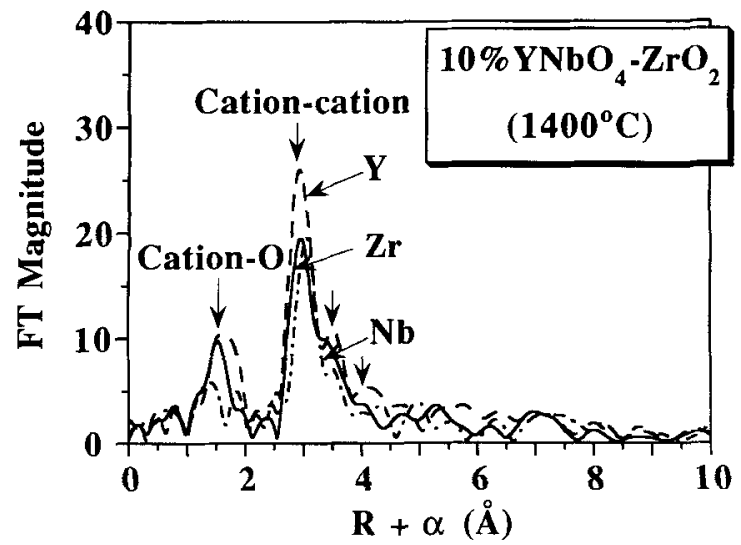

Fig. 6. Fourier transforms of $\mathrm{Zr}, \mathrm{Y}$, and $\mathrm{Nb}$ EXAFS for $m-\mathrm{ZrO}_{2}$ containing $10 \mathrm{~mol} \% \mathrm{YNbO}_{4}$ ( $t$-to- $m$ transformation during cooling after $1400^{\circ} \mathrm{C}$ calcination). consistent with the decrease in the average coordination number for $\mathrm{Zr}(8$ to 7$)$ and $\mathrm{Y}(8$ to 7$)$ and the increase in the average coordination number for $\mathrm{Nb}$ ( 4 to 6 ) from tetragonal to monoclinic zirconia.

\section{(3) XANES Spectra}

$X$-ray absorption near-edge (XANES) spectra at the $\mathrm{Zr}^{-}, \mathrm{Y}-$, and $\mathrm{Nb}-K$ edges for $10 \mathrm{YNb} 08,20 \mathrm{YNb} 08$, and $10 \mathrm{YNb} 14$ are shown in Figs. 8-10, respectively. The spectra at each edge are similar for $10 \mathrm{YNb} 08$ and $20 \mathrm{YNb} 08$, which are both tetragonal, but significantly different for $10 \mathrm{YNb} 14$, which is monoclinic. Thus, the XANES spectra are also phase dependent. The main peak in the $K$-edge spectrum is due to transitions into $p$-symmetry final states. ${ }^{22}$ This occurs when a positively charged (core) hole remains sufficiently unshielded so that it binds the $p$ states and produces exciton levels. This includes both atomic-like transitions (e.g., $1 s \rightarrow 5 p$ ) and "continuum resonances" where the X-ray excited photoelectron is weakly bound by the repulsive potential of the surrounding scatterers. ${ }^{23}$ These XANES features are sensitive primarily to the symmetry and bond length around cations. The disorder in the $\mathrm{Nb}$ site (cf. second peak in Figs. 4 and 5) is therefore expected to give a broad range of continuum resonance energies for the samples calcined at $850^{\circ} \mathrm{C}$. The ordering of $\mathrm{Y}$ and $\mathrm{Nb}$ at $1400^{\circ} \mathrm{C}$ should sharpen these energy spectra for all three elements, especially for $\mathrm{Nb}$. This trend is clearly manifested in Figs. 8-10. The systematic differences in shape between $\mathrm{Y}$ and $\mathrm{Zr}$ for the $850^{\circ} \mathrm{C}$ samples may reflect differences in the relative importance of $1 s \rightarrow 5 p$ and $1 s \rightarrow$ continuum resonance, with the latter (higher energy) transition being less important for the more disordered Y sites.

A small shoulder about $6 \mathrm{eV}$ below the principal peak is marked by an arrow in each figure. It is visible for the $\mathrm{Zr}$ edge, more apparent for the $\mathrm{Nb}$ edge, but barely resolved for the $\mathrm{Y}$ edge in the tetragonal samples. This pre-edge feature is absent in the monoclinic sample. In general, XANES features within ca. $10 \mathrm{eV}$ below the edge threshold are due to electronic transitions to unoccupied high-energy states near the Fermi level. ${ }^{22}$ These transitions are particularly sensitive to the local geometry (first anion neighbors in ionic compounds) of the probe atom. Thus, the difference in the shoulders for $\mathrm{Zr}, \mathrm{Y}$, and $\mathrm{Nb}$ suggests that there are different cation- $O$ geometries for the different cations. Since we have attributed the principle peak of the $K$ edge to a $1 s \longrightarrow 5 p$ dipole-allowed transition, the shoulder in the rising edge may be attributed to a mixing of unoccupied $d$ final states with $p$-character final states. Such $d-p$ mixing is forbidden for a centrosymmetric (e.g., octahedral) environment but is allowed in a noncentrosymmetric (e.g., tetrahedral) environment. Thus, a roughly tetrahedral environment in $\mathrm{Nb}-\mathrm{O}$ in tetragonal solid solutions (Table II) gives a relatively strong shoulder on the $\mathrm{Nb}$ edge in $10 \mathrm{YNb} 08$ and $20 \mathrm{YNb} 08$. Further support for this interpretation comes from our recent study of perovskite niobate structures, ${ }^{24}$ which have an octahedral $\mathrm{NbO}_{6}$ environment and hence no XANES shoulder. The same reasoning can also apply for $\mathrm{Zr}$ for which tetrahedral-like structures are present only in tetragonal zirconia due to a splitting of $\mathrm{ZrO}_{8}$ bonding. ${ }^{12}$ Correspondingly, a weak shoulder on the $\mathrm{Zr}$ edge is characteristic of all the XANES spectra of tetragonal solid solutions (Fig. 8). Other than the above two cases, the remaining cation- $\mathrm{O}$ geometries (the 7 -fold $\mathrm{Zr}-\mathrm{O}$ and $\mathrm{Y}-\mathrm{O}$ coordination in the monoclinic phase, the 6 -fold coordination for $\mathrm{Nb}-\mathrm{O}$ in the monoclinic phase, as well as the $\mathrm{YO}_{8}$ cubiclike structure in the tetragonal phase) apparently have small $d-p$ orbital mixing and thus do not have detectable shoulders on the rising edge.

\section{Discussion}

\section{(1) Local Atomic Structures in $\mathrm{ZrO}_{2}-\mathrm{YNbO}_{4}$}

It has been questioned previously whether $\mathrm{Nb}$ (and $\mathrm{Ta}$ ) occupies substitutional ${ }^{5}$ or interstitial sites in Y-stabilized zirconia solid solutions. ${ }^{6}$ The present results unequivocally support the 

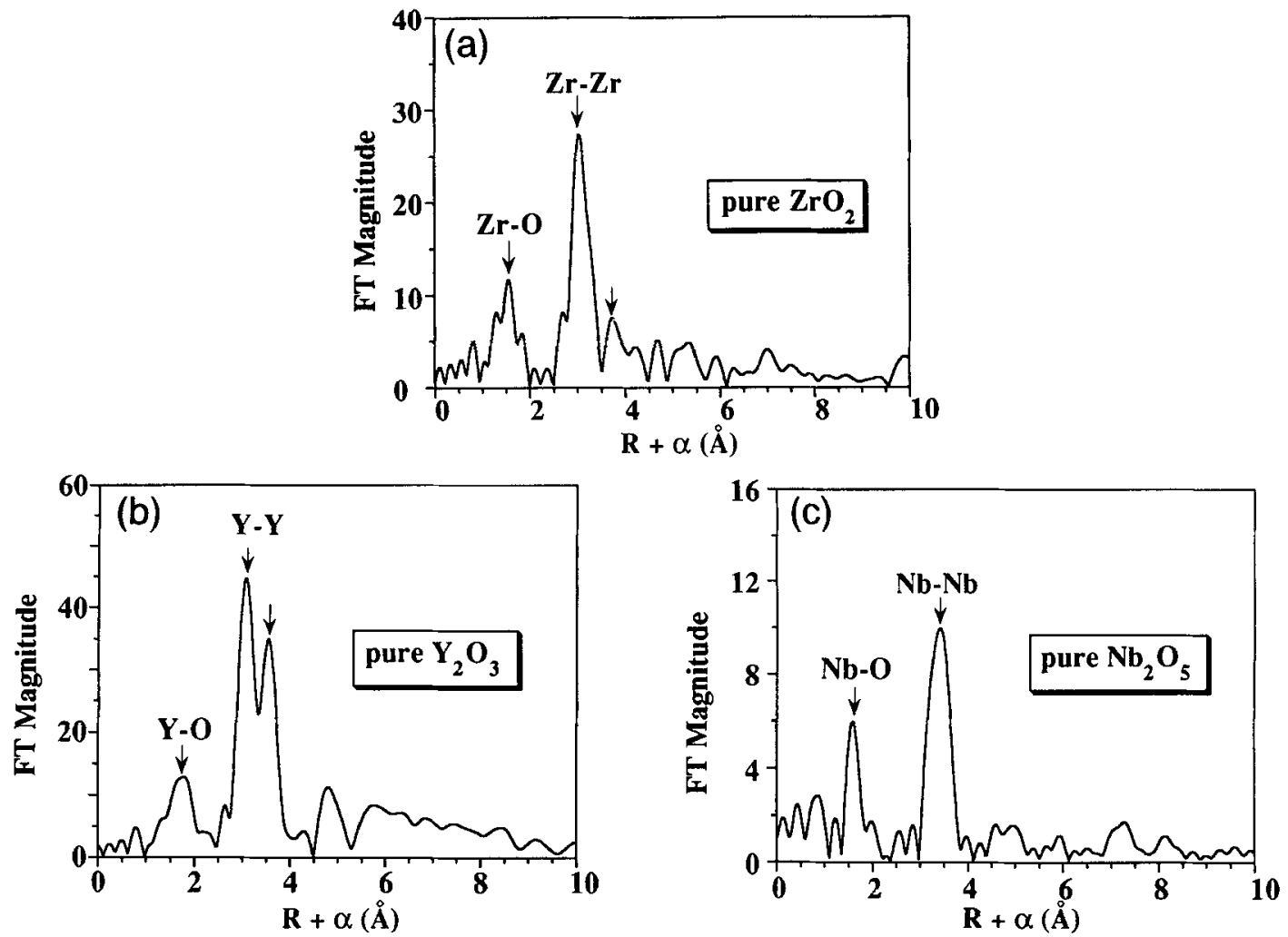

Fig. 7. Fourier transforms of (a) Zr EXAFS for $m-\mathrm{ZrO}_{2}$, (b) Y EXAFS for $\mathrm{Y}_{2} \mathrm{O}_{3}$, and (c) $\mathrm{Nb}$ EXAFS for $\mathrm{Nb}_{2} \mathrm{O}_{5}$.

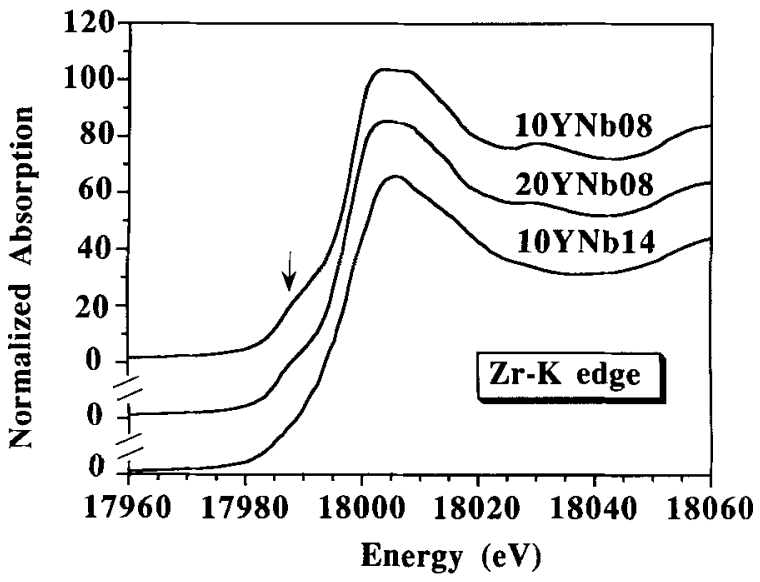

Fig. 8. XANES spectra at $\mathrm{Zr}-K$ edge for $m$ - and $t-\mathrm{ZrO}_{2}$ containing $\mathrm{YNbO}_{4}$ (shifted vertically for clarity).

substitutional model. This solid solution is mostly disordered at low temperature, causing more distortion with increasing $\mathrm{Y}-\mathrm{Nb}$ dopant concentration (e.g., Figs. 4 and 5). At higher temperatures, $\mathrm{Y}$ and $\mathrm{Nb}$ become ordered, causing a substantial decrease in the cation-cation distortion, particularly for $\mathrm{Nb}$. A similar ordering process with a similar change in the amplitude of EXAFS was observed for the $\mathrm{ZrO}_{2}-\mathrm{GeO}_{2}$ system described in the preceding paper. "In both cases ordering occurs at concentrations well below the solubility limit.

Theoretically, ordering in a binary alloy must involve both host ( $\mathrm{Zr}$ ) and solute (Ge) cations, whereas ordering in a ternary alloy could conceivably involve only solute cations, not $\mathrm{Zr}$. This latter option is apparently exercised in the $\mathrm{ZrO}_{2}-\mathrm{YNbO}_{4}$ system. Indeed, at higher $\mathrm{Y}-\mathrm{Nb}$ concentrations (e.g., 20\% $\mathrm{YNbO}_{4}$ ), an ordered phase of monoclinic $\mathrm{YNbO}_{4}$ was observed after $1400^{\circ} \mathrm{C}$ calcination. It is also conceivable that ordering preferentially starts around one cation only. For example, Nb

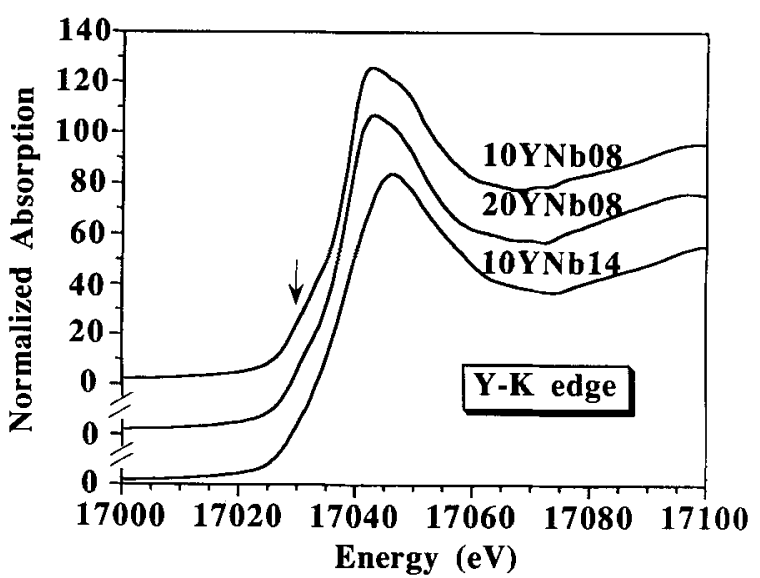

Fig. 9. XANES spectra at $\mathrm{Y}-K$ edge for $m$ - and $t-\mathrm{ZrO}_{2}$ containing $\mathrm{YNbO}_{4}$ (shifted vertically for clarity).

cations may migrate to take up certain preferred sites around $Y$, whereas $Y$ remains randomly distributed. Some evidence in support of this scenario is seen in the "abnormal" $\mathrm{Y}-\mathrm{O}$ distortion which decreases with increasing dopant concentration for $10 \mathrm{YNb} 08$ and $20 \mathrm{YNb} 08$. The $\mathrm{Nb}-\mathrm{O}$ distortion is "normal" for these samples. More fully developed ordering eventually obtains at higher temperatures when $\mathrm{Y}$ cations become mobile. However, even in this case, it is still possible that ordering around $\mathrm{Y}$ is more complete than that around $\mathrm{Nb}$. This could account for the larger amplitude of the $Y$-cation shell for 10YNb14. Similar kinetic consideration can also explain why ordering does not take place in $10 \mathrm{YNb} 08$ but in $10 \mathrm{YNb} 14$, since diffusivity may be too low at low temperature despite a possibly larger driving force.

Dopant-oxygen bond lengths are very different from the $\mathrm{Zr}-\mathrm{O}$ distance, even in solid solutions. This is a general result for all of the dopants that we have investigated. ${ }^{5,11}$ The bond 


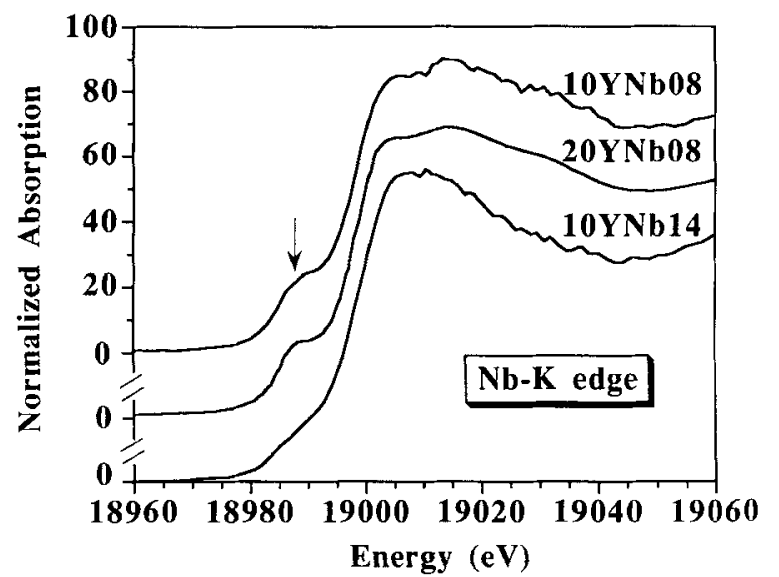

Fig. 10. XANES spectra at $\mathrm{Nb}-K$ edge for $m$ - and $t-\mathrm{ZrO}_{2}$ containing $\mathrm{YNbO}_{4}$ (shifted vertically for clarity).

length of $2.32 \AA$ for $\mathrm{Y}-\mathrm{O}$ is a direct measurement of bond length for 8-fold-coordinated $Y$. (There are no oxygen vacancies in $\mathrm{ZrO}_{2}-\mathrm{YNbO}_{4}$.) Smaller than suggested by Shannon's radii, ${ }^{25}$ it is, nevertheless, consistent with the diffraction data for tetragonal $\mathrm{YNbO}_{4}^{20}$ and is identical to the $\mathrm{Y}-\mathrm{O}$ bond length in tetragonal and cubic zirconia, ${ }^{9,13}$ all of which have $\mathrm{YO}_{8}$ polyhedra. In the monoclinic zirconia, the $\mathrm{Y}-\mathrm{O}$ distance decreases to $2.27 \AA$, also consistent with $\mathrm{MO}_{7}$ polyhedra in monoclinic zirconia.

The $\mathrm{Nb}-\mathrm{O}$ bonding favors an $\mathrm{NbO}_{4}$ polyhedron in tetragonal zirconia. The $\mathrm{Nb}-\mathrm{O}$ distance $(1.90 \AA)$ in the tetragonal zirconia is actually shorter than the $\mathrm{Zr}-\mathrm{O}_{1}$ bond length $(2.10 \AA)$ in the same structure, causing increased tetragonality as discussed in the next subsection. In monoclinic zirconia, the prevalence of $\mathrm{MO}_{7}$ polyhedra for $\mathrm{Zr}$ and $\mathrm{Y}$ seems to force the Nb to adopt a longer average bond length and a higher coordination number. This latter structure is more reminiscent of the parent, and probably more natural, $\mathrm{Nb}_{2} \mathrm{O}_{5}$ structure. Lastly, in the absence of ordering, the undersized $\mathrm{Nb}$ causes severe distortion of the surrounding cation network. This feature is characteristic of other undersized dopants of zirconia solid solutions. ${ }^{9}$

\section{(2) Role of $\mathrm{Nb}^{5+}$ in Stabilizing Zirconia}

Stabilization of the fluorite-type zirconia lattice can be achieved either by oxygen vacancies or by cation network stabilizers. Trivalent dopants stabilize zirconia by the first mechanism, ${ }^{9,13}$ whereas tetravalent dopants stabilize zirconia by the second mechanism. " $\mathrm{Nb}$ doping and $\mathrm{Y}-\mathrm{Nb}$ codoping provide an interesting example that involves both mechanisms.

At low dopant concentrations, $\mathrm{Nb}$ and $\mathrm{Ta}$ are destabilizers for Y-stabilized tetragonal and cubic zirconia ${ }^{6-8}$ because they annihilate the oxygen vacancies introduced by $\mathrm{Y}^{3+}$. Atomistically, this occurs by forming $\mathrm{NbO}_{4}, \mathrm{TaO}_{4}, \mathrm{YO}_{8}$, and $\mathrm{ZrO}_{8}$, in place of $\mathrm{ZrO}_{7}$. The decreased concentration of $\mathrm{ZrO}_{7}$ is directly responsible for the decreased stability of the tetragonal and cubic phases. The removal of oxygen vacancies also has the effect of increasing the tetragonality ${ }^{7,8}$ since the anisotropy of the layer structure of tetragonal zirconia, as supported by the $\mathrm{Zr}-\mathrm{O}_{1}$ and $\mathrm{Zr}-\mathrm{O}_{\mathrm{II}}$ bifurcation, becomes stronger without the disruption of $\mathrm{Zr}$-associated oxygen vacancies."

Codoping of $\mathrm{Y}$ and $\mathrm{Nb}$ to high concentrations has an effect similar to that of $\mathrm{Ge}$ doping. In both cases, they stabilize tetragonal zirconia and increase tetragonality without introducing oxygen vacancies. The cations in both cases tend to order into a common, scheelite-like structure. In the ordered structure, the smaller cations, $\mathrm{Nb}$ and $\mathrm{Ge}$, respectively, adopt a 4-fold coordination leaving 8-fold coordination to the larger cations, and the pattern for cation partition is layerlike. In particular, since the $\mathrm{Ge}-\mathrm{O}$ and $\mathrm{Nb}-\mathrm{O}$ distances are shorter than the $\mathrm{Zr}-\mathrm{O}_{1}$ distance, the bonding anisotropy of the layerlike structure is accentuated, resulting in higher tetragonality. A probable cause for the ordering " is the reduction in strain energy of the highly unstable, internally strained tetragonal lattice, whose instability is rooted in the unfavorable $\mathrm{ZrO}_{8}$ configuration for the relatively small $\mathrm{Zr}$ cations. With the aid of an even smaller cation species which adopts 4-fold coordination, a more favorable packing in the form of an ordered layerlike structure becomes possible and the oxygen overcrowding around $\mathrm{Zr}$ is alleviated. The present observation supports this model.

Ordering involving the smallest (Nb) and largest (Y) cations is apparently sufficient to partially stabilize tetragonal zirconia. The stabilizing effect of $\mathrm{YNbO}_{4}$, however, is less than that of $\mathrm{GeO}_{2}$ for two reasons. First, since ordering in the $\mathrm{ZrO}_{2}-\mathrm{YNbO}_{4}$ system probably extends only to $\mathrm{Y}$ and $\mathrm{Nb}$ and not to $\mathrm{Zr}$, the reduction of strain energy is obviously smaller for $\mathrm{ZrO}_{2}-$ $\mathrm{YNbO}_{4}$. Second, tetragonal $\mathrm{YNbO}_{4}$ is itself an unstable structure that undergoes a tetragonal-to-monoclinic distortion during cooling. ${ }^{26,27}$ This is unlike $\mathrm{ZrO}_{2}-\mathrm{GeO}_{2}$ alloys, $\mathrm{Zr}_{3} \mathrm{GeO}_{8}$ and $\mathrm{ZrGeO}_{4}$, which are stable in the tetragonal form at all temperatures. This expectation of decreased stabilization is in broad agreement with the experimental transformation temperatures. ${ }^{6.728}$ Lastly, a comparison of the tetragonality of $\mathrm{YNbO}_{4}$ $(0.0605),{ }^{27} \mathrm{Zr}_{3} \mathrm{GeO}_{8}(0.0442),{ }^{29} \mathrm{ZrGeO}_{4}(0.0841),{ }^{29}$ and $t-\mathrm{ZrO}_{2}$ $(0.0202)^{30}$ is instructive. At a comparable $\mathrm{Nb} / \mathrm{Ge}$ atomic fraction, the tetragonality of $\mathrm{YNbO}_{4}$ is less than that of $\mathrm{ZrGeO}_{4}$. Likewise, the effect of $\mathrm{YNbO}_{4}$ doping on the tetragonality of $t-\mathrm{ZrO}_{2}$ is less than that of $\mathrm{GeO}_{2}$ doping. (The increase in tetragonality is 0.0002 per mol\% $\mathrm{Nb}$ doping versus 0.0005 per mol\% Ge doping.) Using our model, these differences are understandable given the different bond distances $(1.90 \AA$ for $\mathrm{Nb}-\mathrm{O}$ versus $1.81 \AA$ for $\mathrm{Ge}-\mathrm{O}$ ) and hence bond strengths (stronger for $\mathrm{Ge}-\mathrm{O})$ for the two dopants.

\section{Conclusions}

(1) $\mathrm{ZrO}_{2}$ and $\mathrm{YNbO}_{4}$ form a substitutional solid solution in both tetragonal and monoclinic form. All three cations ( $\mathrm{Zr}, \mathrm{Y}$, and $\mathrm{Nb}$ ) have a similar cation-cation distance but very different cation-oxygen coordination. This is consistent with the behavior of other substitutional solid solutions. ${ }^{9.11}$

(2) $\mathrm{Nb}$ in tetragonal zirconia is tetrahedrally coordinated with a shorter $\mathrm{Nb}-\mathrm{O}$ bond length than that of $\mathrm{Zr}-\mathrm{O}_{\mathrm{r}}$. In random distribution, this undersized cation causes severe distortion in its surrounding cation environment as evidenced by a very weak EXAFS amplitude associated with $\mathrm{Nb}$-cation scattering. This is also consistent with the behavior of other undersized dopants in zirconia solid solutions."

(3) $Y$ in tetragonal zirconia has 8 -fold oxygen coordination with a distance of $2.32 \AA$. This is in agreement with our previous study of this system in the tetragonal and cubic form in the absence of $\mathrm{Nb}$. The direct verification of the $\mathrm{Y}-\mathrm{O}$ distance in 8 -fold coordination lends support to our structural picture that oxygen vacancies in $\mathrm{ZrO}_{2}-\mathrm{Y}_{2} \mathrm{O}_{3}$ are not associated with $\mathrm{Y}^{9.13}$

(4) $\mathrm{Y}-\mathrm{Nb}$ ordering in tetragonal zirconia into a scheelitelike arrangement probably takes place at high temperatures $\left(1400^{\circ} \mathrm{C}\right.$ in this study) and well within the solubility limit. The ordering reduces the large strain energy inherent in the $t-\mathrm{ZrO}_{2}$ structure. The ordered structure is layerlike and the 4-fold-coordinated $\mathrm{Nb}-\mathrm{O}$ bonding is stronger than that of $\mathrm{Zr}-\mathrm{O}_{1}$, resulting in an increase in the anisotropy of the parent $t-\mathrm{ZrO}_{2}$ layer structure and its tetragonality. This picture is consistent with that used to explain the stability and tetragonality of $\mathrm{ZrO}_{2}-\mathrm{GeO}_{2}$ solid solution, where Ge also favors tetrahedral coordination.

\section{References}

'I. K. Naik and T. Y. Tien, "Electrical Conduction in $\mathrm{Nb}_{2} \mathrm{O}_{5}$-doped Cerium Dioxide," I. Electrochem. Soc., 126 [4] 562-66 (1979).

'R. S. Roth and L. W. Coughanour; p. 144 in Phase Diagram for Ceramists, Vol. 1. Edited by E. M. Levin, C. R. Robbins, and H. F. McMurdie. American Ceramic Society, Columbus, OH, 1964.

${ }^{3}$ B. W. King, J. Schulz, E. A. Durbin, and W. H. Duckworth; p. 144 in Phase Diagram for Ceramists, Vol. 1. Edited by E. M. Levin, C. R. Robbins, and H. F. McMurdie. American Ceramic Society, Columbus, OH, 1964 
${ }^{4} \mathrm{~S}$. Prietzel, L. J. Gauckler, and G. Petzow, "Stabilizing of Cubic $\mathrm{ZrO}_{2}$ in the System $\mathrm{ZrO}_{2}-\mathrm{MgO}-\mathrm{Ta}_{2} \mathrm{O}_{5}$ and Its Electrical Conductivity"; pp. 725-30 in Science of Ceramics, Vol. 9. Edited by $\mathrm{H}$. Hausner. Deutsche Keramische Gesellschaft, Weiden, Germany, 1980.

${ }^{5} \mathrm{C}$. B. Choudhary and E. C. Subbarao, "Electrical Conduction in the Cubic Fluorite Phase in the System $\mathrm{ZrO}_{2}-\mathrm{YO}_{15}-\mathrm{TaO}_{25}$ "; pp. 665-68 in Fast Ion Transport in Solids. Edited by P. Vashishta, J. N. Mundy, and G. K. Shenoy. Elsevier/ North-Holland, New York, 1979.

${ }^{6}$ D. J. Kim and T. Y. Tien, "Phase Stability and Physical Properties of Cubic and Tetragonal $\mathrm{ZrO}_{2}$ in the System $\mathrm{ZrO}_{2}-\mathrm{Y}_{2} \mathrm{O}_{3}-\mathrm{Ta}_{2} \mathrm{O}_{5}$," J. Am. Ceram. Soc., 74, 3061-65 (1991).

${ }^{7}$ D. J. Kim, "The Effect of Alloying on the Transformability of $\mathrm{Y}_{2} \mathrm{O}_{3}$ Stabilized Tetragonal $\mathrm{ZrO}_{2}$ "; Ph.D. Thesis. University of Michigan, Ann Arbor, MI, 1988.

${ }^{*}$ D. J. Kim, "Effect of $\mathrm{Ta}_{2} \mathrm{O}_{5}, \mathrm{Nb}_{2} \mathrm{O}_{5}$ and $\mathrm{HfO}_{2}$ Alloying on the Transformability of $\mathrm{Y}_{2} \mathrm{O}_{3}-$ Stabilized Tetragonal $\mathrm{ZrO}_{2}, " J . A m$. Ceram. Soc., 73, 115-20 (1990).

${ }^{9} \mathrm{P}$. Li, I-W. Chen, and J. E. Penner-Hahn, "The Effect of Dopants on Zirconia Stabilization-An X-ray Absorption Study: I, Trivalent Dopants," J.Am. Ceram Soc., 77 [1] 118-28 (1993).

"T. S. Sheu, "Phase Stability of Zirconia Solid Solutions"; Ph.D. Thesis. University of Michigan, Ann Arbor, MI, 1989.

"P. Li, I-W. Chen, and J. E. Penner-Hahn, "The Effect of Dopants on Zirconia Stabilization-An X-ray Absorption Study: II, Tetravalent Dopants," J. Am. Ceram. Soc., 77 [5] 1281-88 (1994).

${ }^{12} \mathrm{P}$. Li, I-W. Chen, and J. E. Penner-Hahn, "X-ray Absorption Studies of Zirconia Polymorphs. I. Characteristic Local Structure,” Phys. Rev. B, 48 [14] 10063-73 (1993).

${ }^{13}$ P. Li, I-W. Chen, and J. E. Penner-Hahn, "X-ray Absorption Studies of Zirconia Polymorphs. II. Effect of $\mathrm{Y}_{2} \mathrm{O}_{3}$ Dopant on Zirconia Structure," Phys. Rev. $B, 48$ [14] 10074-81 (1993).

${ }^{14}$ J. J. Rehr, J. Mustre de Leon, S. I. Zabinsky, and R. C. Albers, "Theoretical X-ray Absorption Fine Structure Standards," J.Am. Chem. Soc., 113, 5135 (1991).

${ }^{15}$ D. K. Smith and H. W. Newkirk, "The Crystal Structure of Baddeleyite (Monoclinic $\mathrm{ZrO}_{2}$ ) and Its Relation to the Polymorphism of $\mathrm{ZrO}_{2}$," Acta Crystallogr., 18, 983-91 (1965).
${ }^{16} \mathrm{M}$. Faucher and J. Pannetier, "Reinforcement of the $\mathrm{Y}_{2} \mathrm{O}_{3}$ Structure at $77 \mathrm{~K}$," Acta Crystallogr., B36, 3209-11 (1980).

${ }^{17} \mathrm{~S}$. Anderson, "The Crystal Structure of $\mathrm{N}-\mathrm{Nb}_{2} \mathrm{O}_{5}$," Inorg. Chem., 351, 10612 (1967).

${ }^{18} \mathrm{~B}$. K. Teo, EXAFS: Basic Principles and Data Analysis. Springer-Verlag, New York, 1986.

${ }^{19} \mathrm{P}$. Li, I-W. Chen, and J. E. Penner-Hahn, "X-ray Absorption Studies of Zirconia Polymorphs. III. Static Distortion and Thermal Distortion," Phys. Rev. B, 48 [14] 10082-89 (1993).

${ }^{20}$ A. I. Komkov, "The Structure of Natural Fergusonite, and of a Polymorphic Modification," Kristallografiya, 4, 836-41 (1959).

${ }^{21} \mathrm{I}$-W. Chen, Y. H. Chiao, and K. Tsuzaki, "Statistics of Martensitic Nucleation," Acta Metall, 33, 1827-45 (1985).

${ }^{22}$ J. C. J. Bart, "Near-Edge X-ray Absorption Spectroscopy in Catalysis," Adv. Catal., 34, 203-97 (1986).

${ }^{27}$ C. R. Natoli, "Distance Dependence of Continuum and Bound State of Excitonic Resonances in X-ray Absorption Near Edge Structure (XANES)"; pp. 44244 in EXAFS and Near Edge Structure III. Edited by K. O. Hodgson, B. Hedman, and J. E. Penner-Hahn. Springer-Verlag, New York, 1984.

${ }^{24} \mathrm{P}$. Li, Y. Wang, and I-W. Chen, "Local Atomic Structures of $\mathrm{Pb}\left(\mathrm{Zn}_{1 / 2}\right.$ $\left.\mathrm{Nb}_{2 / 3}\right) \mathrm{O}_{3}$ and Related Perovskites. 1. An XANES Study of lonicity/Covalency," Ferroelectricity, in press.

${ }^{25}$ R. D. Shannon, "Revised Effective Ionic Radii and Systematic Studies of Interatomic Distances in Halides and Chalcogenides," Acta Crystallogr., A32, $751-67$ (1976).

${ }^{26}$ V. S. Stubican, "High-Temperature Transitions in Rare-Earth Niobates and Tantalates," J. Am. Ceram. Soc., 47, 55-58 (1964)

${ }^{27}$ H. P. Rouksby and E. A. D. White, "The Structures of $1: 1$ Compounds of Rare Earth Oxides with Niobia and Tantala," Acta Crystallogr, 16, 888 (1963).

${ }^{28}$ J. Lefevre, "Fluorite-Type Structural Phase Modifications in Systems Having a Zirconium or Hafnium Oxide Base," Ann. Chim., 8, $117-49$ (1963).

${ }^{29}$ A. Ennaciri, D. Michel, M. Perez y Torba, and J. Pannetier, "Neutron Diffraction Determination of the Structure of an Ordered Scheelite-Type: $\mathrm{Zr}_{3} \mathrm{GeO}_{8}$," Mater. Res. Bull., 19, 793-99 (1984).

${ }^{31}$ M. Yoshimura, M. Yashima, T. Noma, and S. Somiya, "Formation of Diffu sionlessly Transformed Tetragonal Phases by Rapid Quenching of Melts in $\mathrm{ZrO}_{2}-\mathrm{RO}_{1.5}$ Systems (R = Rare Earth),"J. Mater. Sci., 25, 201 I-16 (1990). 